PURBaWIdya: Jurnal Penelitian dan Pengembangan Arkeologi

p-ISSN: 2252-3758, e-ISSN: 2528-3618 — Terakreditasi Kementerian Ristekdikti No. 147/M/KPT/2020

Vol. 10 (2), November 2021, pp 155-166 DOI: https://doi.org/10.24164/pw.v10i2.392

\title{
DAS NGROWO-NGASINAN: PENGARUH DAN MANFAATNYA TERHADAP TINGGALAN ARKEOLOGI DI TRENGGALEK ${ }^{1}$
}

\section{THE NGROWO-NGASINAN WATERSHED: EFFECT AND BENEFITS OF ARCHAEOLOGICAL REMAINS IN TRENGGALEK}

\author{
Hery Priswanto \\ Balai Arkeologi Provinsi D.I. Yogyakarta \\ Jalan Gedongkuning No. 174 Yogyakarta 55171 Indonesia \\ e-mail: priswanto.balaryk@gmail.com \\ Naskah diterima: 17-02-2021 - Revisi terakhir: 15-08-2021 \\ Disetujui terbit: 30-11-2021 - Tersedia secara online: 30-11-2021
}

\begin{abstract}
The Ngrowo-Ngasinan watershed is one of the Brantas watersheds covering an area of 1,188,800 hectares located in the Trenggalek Regency. The Ngrowo-Ngasinan watershed consists of forests, fields, irrigated rice fields, plantations, and settlements which are flooded every year. Flood conditions that occur have an influence on archaeological remains around the Ngrowo-Ngasinan watershed, namely Brongkah Temple, Semarum Site and Kamulan. Most of the archaeological remains are buried by alluvial deposits due to flooding and the overflow of the Ngrowo - Ngasinan River. The results of research conducted by Balar DIY in 2012-2015 through survey and excavation data collection methods indicate that the Semarun and Kamulan sites were abandoned because they were inundated and drowned due to the overflow (flood) of the Ngrowo and Ngasinan rivers. The purpose of this article is to determine the effect of the existence of the NgrowoNgasinan watershed on the loss or damage of archaeological sites around the NgrowoNgasinan watershed. Morphologically, the archaeological sites in the Ngrowo-Ngasinan watershed have a very ideal position as a place of settlement, because their location is in a basin and sloping area, fertile, and close to water sources. The conclusion should be at the end of the abstract. Avoid the word 'disaster' (adjust title). Conclusion: The selection of residential locations around the Ngrowo-Ngasinan watershed has a very significant impact or great risk for flood disasters because of its location on the banks of the river.
\end{abstract}

Keywords: Ngrowo-Ngasinan Watershed, archaeological remains, flood.

\begin{abstract}
Abstrak
DAS Ngrowo-Ngasinan merupakan salah satu DAS Brantas seluas 1.188.800 ha yang berada di wilayah Kabupaten Trenggalek. DAS Ngrowo-Ngasinan berupa hutan, tegalan, sawah irigasi, perkebunan, dan permukiman yang setiap tahunnya mengalami banjir. Kondisi banjir yang terjadi mempunyai pengaruh terhadap tinggalan arkeologi yang berada di sekitar DAS Ngrowo-Ngasinan, yaitu Candi Brongkah, Situs Semarum, dan Kamulan. Tinggalan arkeologi tersebut sebagian besar dalam kondisi tertimbun endapan aluvial akibat banjir dan meluapnya Sungai Ngrowo-Ngasinan. Hasil penelitian yang dilakukan oleh Balar DIY tahun 2012--2015 melalui metode pengumpulan data survei dan ekskavasi menunjukkan indikasi bahwa Situs Semarun dan Kamulan ditinggalkan karena tergenang dan tenggelam akibat meluapnya (banjir) Sungai Ngrowo dan Ngasinan. Tujuan penulisan artikel ini adalah untuk mengetahui pengaruh keberadaan DAS Ngrowo-Ngasinan terhadap hilang atau rusaknya situs-situs arkeologi di sekitar DAS Ngrowo-Ngasinan. Secara morfologis, situs-situs arkeologi yang terdapat di DAS
\end{abstract}

${ }^{1}$ Artikel ini sudah dipresentasikan pada Seminar Nasional Arkeologi tahun 2020 "Petaka dalam kehidupan manusia" di Hotel Aston Bandung, 18-20 November 2020 
Ngrowo-Ngasinan mempunyai keletakan yang sangat ideal sebagai tempat permukiman karena lokasinya berada di daerah cekungan dan landai, subur, serta dekat dengan sumber air. Pemilihan lokasi permukiman di sekitar DAS Ngrowo-Ngasinan membawa dampak yang sangat signifikan atau risiko besar terhadap bencana banjir karena lokasinya yang berada di tepi sungai.

Kata kunci: DAS Ngrowo-Ngasinan, tinggalan arkeologi, banjir

\section{PENDAHULUAN}

Dalam sejarah peradaban manusia, terdapat bukti-bukti bahwa pusat peradaban yang paling tua ditemukan di sepanjang DAS di lembah Sungai Nil di Mesir, Eufrat dan Tigris di Mesopotamia, Indus di India, serta Hoangho dan Yang Tse di Cina. Kehidupan dan permukiman di sepanjang DAS tersebut kemudian melahirkan peradaban-peradaban besar. Hal ini sesuai dengan yang diungkapkan oleh Toynbe bahwa lingkungan fisik dan lingkungan manusia mewujudkan stimulasi bagi lahirnya suatu peradaban (Daldjoeni, 1984). Pengelolaan sungai yang kurang baik dapat menyebabkan bencana banjir. Banjir adalah fenomena alam yang sulit diduga oleh manusia karena datangnya secara tiba-tiba dengan priodisitas yang tidak menentu, kecuali daerah yang sudah menjadi langganan banjir. Banjir merupakan sebuah kondisi ketika aliran air yang jatuh secara tidak maksimal tertampung oleh palung sungai (Daniati, 2015). Bencana banjir disebabkan adanya beberapa faktor yang memengaruhi, seperti membuang sampah di sungai dan menebang pohon; dampak tersebut akan mengancam eksistensi organisme hidup (Sumarkanto, 2002). Faktor lain yang ditimbulkan dari banjir adalah iklim dan curah hujan yang tinggi, khususnya daerah dataran rendah ke pegunungan. (Yusuf, 2005).

Kabupaten Trenggalek merupakan salah satu wilayah di bagian selatan dari wilayah provinsi Jawa Timur dan terletak pada koordinat $111^{\circ} 24^{\prime}$ hingga $112^{\circ} 11^{\text {' }}$ bujur timur dan $70^{\circ} 63^{\prime}$ ' hingga $80^{\circ} 34^{\prime}$ lintang selatan. Kabupaten Trenggalek memiliki 28 sungai dengan panjang antara 2,00 km hingga 41,50 km (Ma'ruf, 2020: 10-11). Pada wilayah Kabupaten Trenggalek terdapat banyak aliran sungai, baik besar maupun kecil. Sungai Ngasinan merupakan muara beberapa sungai yang cukup besar, yaitu dari utara Sungai Bagong yang bermuara di Kelurahan Tamanan dan Sungai Prambon yang bermuara di Kecamatan Tugu, dan barat Sungai Pinggir yang bermuara di Kecamatan Tugu dan dari selatan Sungai Nglongah (Mlinjon) yang bermuara di Kecamatan Trenggalek. Sebelum masuk Dam Dawung, sungai menyatu dengan Sungai Munjungan. Sungai-sungai yang berada di DAS Brantas sebagian besar digunakan untuk irigasi dan sebagian masuk ke PLTA Niyama. Di beberapa anak sungai di Sub-DAS Ngrowo, seperti Sungai Tawing dan Sungai Ngasinan di Kabupaten Trenggalek sering terjadi banjir setiap tahun karena faktor curah hujan yang tinggi dan faktor topografi. Kabupaten Trenggalek terdiri dari $2 / 3$ wilayah pegunungan dan 1/3 wilayah dataran rendah dengan ketinggian antara 0 sampai dengan 1.250 meter di atas permukaan laut (Rahman, 2016).

Kabupaten Trenggalek dengan kondisi topografi, geologi, tanah, dan tata guna lahan sub-DAS Ngrowo-Ngasinan meliputi Kecamatan Gandusari dan Kampak. Kedua 
kecamatan tersebut terletak di daerah dataran tinggi sepanjang Gunung Wilis yang memiliki kemiringan lereng antara $7^{\circ}-39^{\circ}$. Geologi sub-DAS Kali Ngrowo-Ngasinan terdiri atas holocene volcanic rock dan tertiary sedimentary rock. Tata guna lahan yang terdapat di sub-DAS Kali Ngrowo-Ngasinan adalah hutan, tegalan, sawah irigasi, perkebunan, dan permukiman dengan persentase tertinggi adalah sawah irigasi dan permukiman (Erlina, 2018).

Pada tahun 2019 terjadi banjir yang diakibatkan hujan deras yang bercampur dengan luapan sungai yang telah melanda beberapa kecamatan di Kabupaten Trenggalek, yaitu Kecamatan Ngantru, Karangan, Suruh, dan Panggul. Ketinggian air di jalan dan rumah warga mencapai 2 meter. Banjir tersebut diakibatkan oleh curah hujan yang tinggi sehingga menyebabkan Sungai Ngasinan tidak dapat menampung debit air. Faktor lain penyebab banjir di Kabupaten Trenggalek tersebut adalah akibat proses sedimentasi di Sungai Ngasinan yang tergolong sangat parah (Latief, 2019).

Artikel ini bertujuan untuk menyampaikan informasi mengenai beberapa tinggalan arkeologi di Kabupaten Trenggalek, seperti Candi Brongkah dan situs-situs di sekitar Sungai Ngasinan (Gambar 1) yang terdampak akibat efek dan pengaruh banjir yang pernah terjadi. Metode penelitian yang digunakan adalah survei dan ekskavasi yang mengacu pada referensi hasil penelitian Balai Arkeologi Yogyakarta tahun 20122015, yaitu untuk mencari jawaban permasalahan yang diajukan.

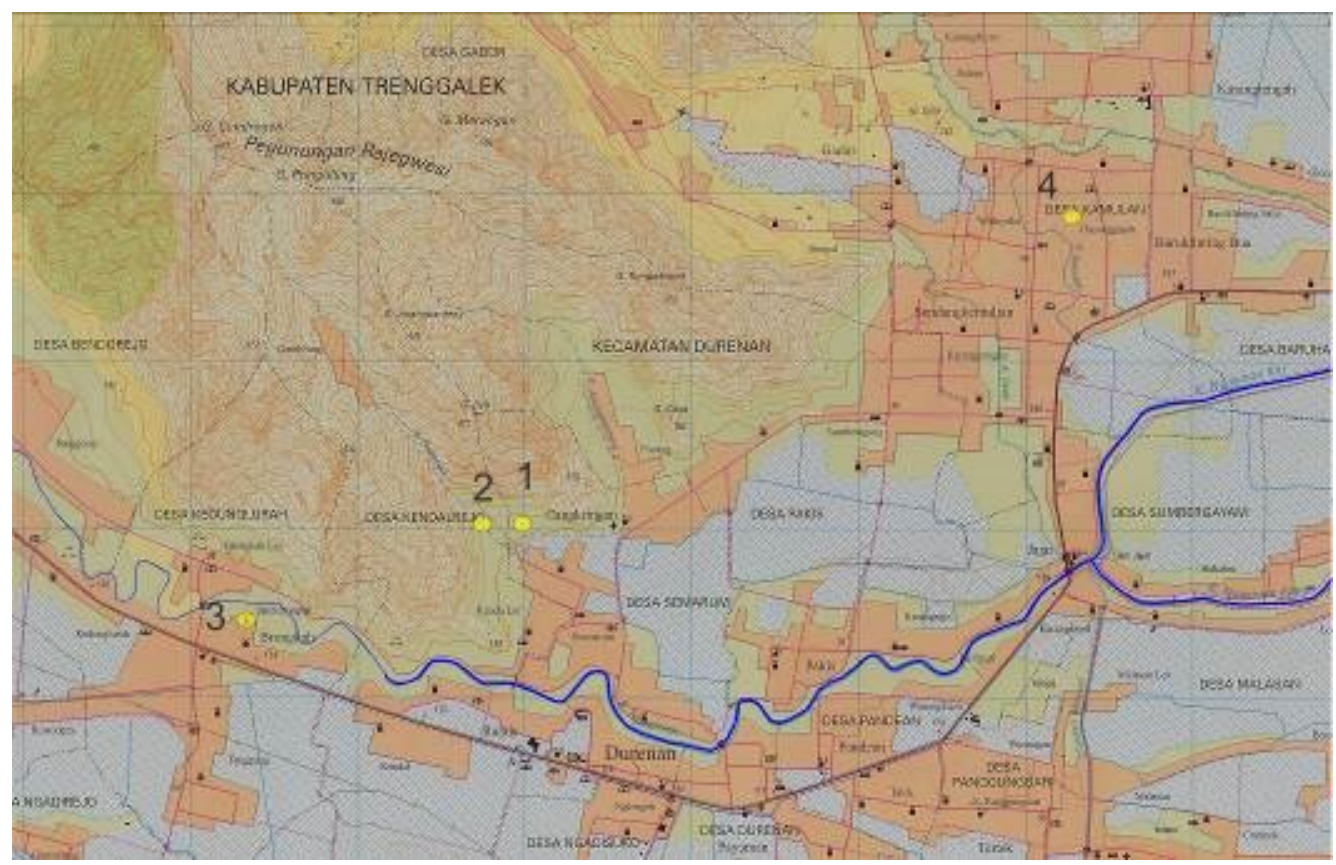

Gambar 1. Situs-Situs Arkeologi di Sepanjang DAS Ngasinan (Sumber: Peta RBI)

Data dan hasil penelitian diperoleh dari penelitian arkeologi yang dilakukan secara intensif oleh Balai Arkeologi Provinsi DIY yang dilakukan di wilayah Kecamatan Durenan pada tahun 2012-2015, yaitu di Situs Semarum dan Situs Kamulan (Priswanto, 2012, 2013, 2014, 2015a). 


\section{METODE}

Dengan mengutamakan kajian data daripada mengutamakan penerapan konsep, hipotesis, dan teori, tipe penelitian di wilayah Kabupaten Trenggalek, khususnya Situs Semarum dan Kamulan ini mengarah pada tipe penelitian deskriptif-analitis. Model penelitian ini bertujuan menemukan fakta empiris guna memberikan gambaran umum tentang suatu fakta atau gejala tertentu yang diperoleh dalam penelitian (Tanudirjo, 1988: 34) yang selanjutnya dirumuskan dalam bentuk simpulan melalui proses deskripsi sistematis, klasifikasi, dan analisis terhadap data arkeologis (Tanudirjo, 1988; Kusumohartono, 1987).

Pengumpulan data dilakukan melalui dua sumber, yaitu sumber primer dan sumber sekunder. Sumber primer adalah data yang diperoleh dengan mengamati objek secara langsung di lapangan melalui kegiatan survei lingkungan fisik dan ekskavasi, sedangkan sumber sekunder adalah data yang diperoleh secara tidak langsung, misalnya melalui laporan-laporan hasil survei, tulisan, atau penelitian sebelumnya (Piggot, 1958: 13). Pengamatan langsung terhadap sumber primer dilakukan dengan mengamati fenomena fisiografis lingkungan di Situs Semarum dan Situs Kamulan serta daerah di sekitarnya. Pengamatan sumber sekunder dilakukan juga dengan membaca beberapa laporan dan berita dari media massa daring yang memberitakan Situs Semarum dan Situs Kamulan serta peristiwa banjir yang melanda di Kabupaten Trenggalek.

\section{PEMBAHASAN}

Menurut Munandar (2015), pada masa Majapahit (Abad XIII-XV Masehi) banyak situs atau candi yang dibangun di area yang dianggap baik sebagai tempat untuk mendirikan bangunan suci. Tempat-tempat itu antara lain

a. dekat sumber air, adanya mata air, danau, daerah aliran sungai, genangan air luas, dan lebih baik adalah lahan di dekat pertemuan dua aliran sungai;

b. di kawasan dataran tinggi yang subur dan mempunyai banyak sumber air;

c. di lereng-lereng gunung yang berhutan rimbun yang menandakan kesuburan;

d. di tepian persawahan luas subur dan dataran yang dialiri banyak sungai kecil (Munandar, 2015: 169).

Beberapa situs arkeologi di Trenggalek, dengan memperhatikan kriteria di atas, diketahui sebagian besar berada di sepanjang Sungai Ngasinan. Keberadaan badan air seperti sungai, kolam, danau, dan mata air tersebut akan dimanterai oleh para pendeta untuk dijadikan air amerta sebagai sarana upacara pemujaan dewa. Oleh karena itu, bangunan candi juga bermakna kesuburan wilayah sehingga tempat suatu candi atau situs didirikan merupakan wilayah yang subur. Di wilayah yang subur itulah dewa-dewa banyak bersemayam dan dapat dipuja oleh manusia (Munandar, 2015: 170).

\section{Situs-Situs Arkeologi di Sekitar DAS Ngasinan}

\section{Candi Brongkah}

Candi Brongkah terletak di Dusun Brongkah, Desa Kedunglurah, Kecamatan Pogalan, Kabupaten Trenggalek. Secara astronomis, Candi Brongkah terletak pada

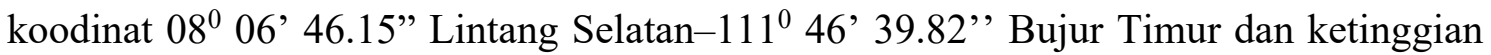


104 meter dpal. Candi Brongkah ini merupakan satu-satunya tinggalan bangunan candi yang dijumpai di Kabupaten Trenggalek. Lokasi Candi Brongkah tidak jauh dari jalan arteri Trenggalek-Tulungagung, yaitu sekitar $3 \mathrm{~km}$ sebelah barat Situs Semarum.

Candi Bongkah adalah sebuah bangunan candi berbahan bata. Posisi bangunan candi sekarang terletak di kedalaman 3 meter di bawah permukaan tanah. Banjir yang berulang-ulang pada Sungai Ngasinan diduga merupakan salah satu penyebab tertimbunnya candi Brongkah pada saat ini (Utomo, 2012). Denah bangunan Candi Brongkah berbentuk bujursangkar dengan ukuran 4 meter x 4 meter dan diperkirakan luas bangunan sekitar 16 meter $^{2}$ (Gambar 2). Berdasarkan pola hias batu-batu berelief, diduga bahwa bangunan Candi Brongkah merupakan bangunan candi masa Majapahit yang bercorak agama Hindu (Siagian, 2002).

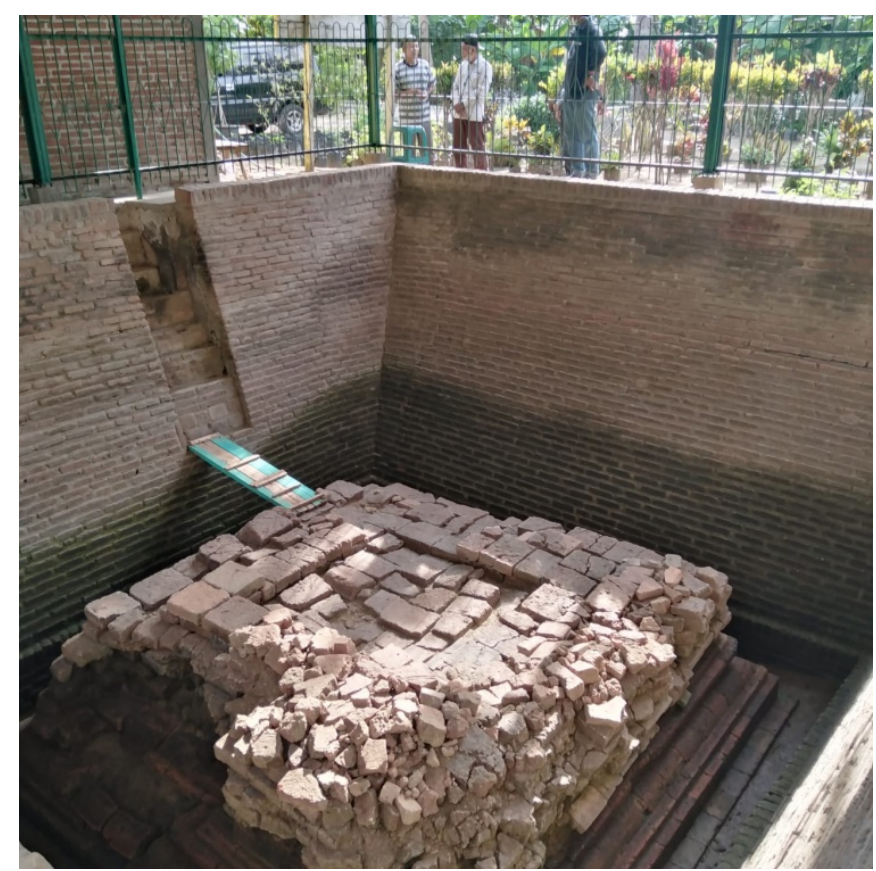

Gambar 2. Candi Brongkah (Sumber: Dokumen Balai Arkeologi Provinsi D.I. Yogyakarta, 2020)

Kondisi bangunan candi ini masih menyisakan bagian kaki candi dan sedikit bagian tubuh bagian bawah saja. Bahan penyusun bangunan candi berupa bata dengan ukuran panjang 32--34 cm, lebar 22--26 cm, dan tebal 7,5--8 cm (Priswanto, 2012).

\section{Situs Semarum}

Situs Semarum terletak pada koordinat $08^{0} 06^{\prime} 42.96$ " Lintang Selatan dan $111^{0}$ 47' 34.93" Bujur Timur pada ketinggian 101 meter dari permukaan laut (dpl). Situs Semarum merupakan sebuah situs arkeologi dengan temuan berupa singkapan struktur bata yang berorientasi Timur-Barat (Utomo, 2012). Bentuk dan karakter Situs Semarum yang terletak di Desa Semarum dipengaruhi oleh kondisi lingkungan yang berada di dataran rendah dengan sisi utara dibatasi oleh Gunung Bale dan di sisi selatan dibatasi oleh Sungai Ngasinan. 


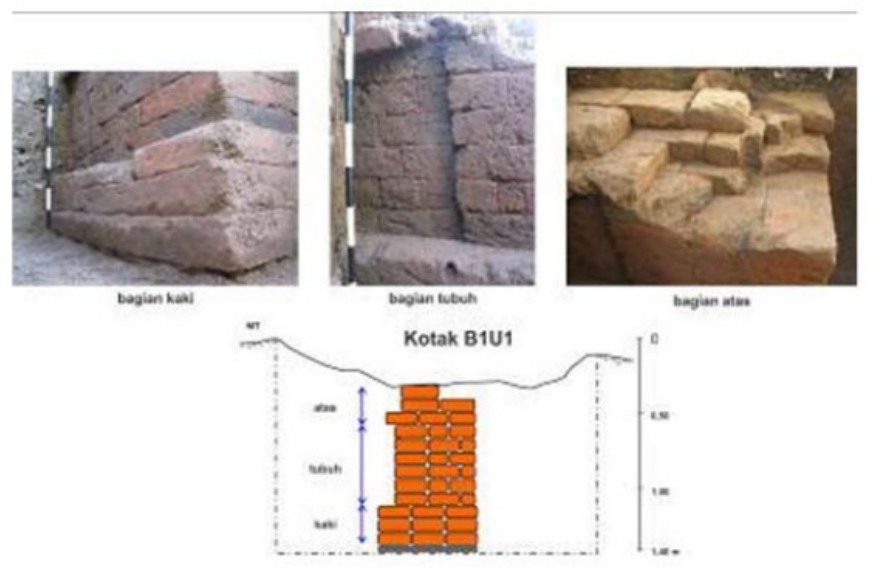

Gambar 3. Konstruksi Struktur Bata di Situs Semarum (Sumber: Dokumen Balai Arkeologi Provinsi D.I. Yogyakarta, 2012)

Berdasarkan analisis morfologi, Situs Semarum mempunyai denah bujur sangkar dengan ukuran 24 m x 24 meter dengan luas 576 meter persegi (Gambar 3). Hasil rekonstruksi grafis diduga bahwa karakter Situs Semarum sebagai situs segaran atau reservoir didasarkan pada bentuknya yang relatif besar dan luas. Temuan struktur bata pada awalnya diduga sebagai bangunan pagar, tetapi berdasarkan hasil penelitian tahun 2014 diduga bahwa fungsi Situs Semarum merupakan sebuah bangunan yang berkaitan dengan bangunan air kuno (ancient hydraulic structure), yaitu reservoir yang secara umum berfungsi sebagai penampung air (Priswanto, 2015c)

Indikasi dugaan Situs Semarum sebagai bangunan air adalah dijumpainya sebuah lubang pembuangan air di bagian sudut timur laut struktur bata, bandul jala yang terbuat dari tanah liat bakar, serta lapisan pasir dan kerakal hasil sedimentasi di bagian dalam struktur bata. Informasi adanya lapisan pasir dan kerakal ini juga dijumpai di Situs Kolam Segaran Trowulan yang pada bagian dasar kolam juga dijumpai data berupa pasir dan batu kali (Siagian, 2002: 197).

\section{Runtuhan Bata Kuno di Desa Kendalrejo}

Di sebelah barat Situs Semarum, yaitu sekitar 220 meter ditemukan runtuhan bata-bata kuno dengan ukuran yang cukup besar. Ukuran bata yang masih dapat dilacak mempunyai panjang 35--36 cm, lebar 22--27 cm, dan tebal 9,5-11 cm. Runtuhan bata kuno tersebut berada di lokasi penambangan tanah untuk bahan pembuatan genteng dan bata, tepatnya di sebelah barat Sungai Ngasinan yang berjarak 10 meter. Debit air sungai di lokasi runtuhan bata kuno ini cukup deras pada saat musim penghujan. Secara administratif, lokasi ini berada di Desa Kendalrejo, Kecamatan Durenan, Kabupaten Trenggalek.

Lokasi runtuhan bata kuno ini merupakan tempat untuk kegiatan upacara bersih desa oleh masyarakat setempat yang kemudian disebut dengan Danyangan Timo (Gambar 4). Informasi dari masyarakat setempat menyatakan bahwa dahulu di lokasi ini juga dijumpai sebuah pohon Timo yang cukup besar, kemudian ditebang untuk dimanfaatkan sebagai sokoguru salah satu bangunan masjid di wilayah Durenan. 
Berdasarkan pengamatan, bata-bata kuno yang dijumpai di Danyangan Timo ini mempunyai bentuk dan ukuran yang sama dengan bata kuno yang dijumpai di Situs Semarum. Selain itu, dijumpai sebuah bata yang mempunyai profil pada bagian sudut, tetapi sudah dalam kondisi tidak utuh lagi. Sebelum rusak, diduga runtuhan bata-bata kuno ini merupakan sebuah bangunan kuno yang juga menggunakan bata sebagai bahan penyusunnya (Priswanto, 2015b).

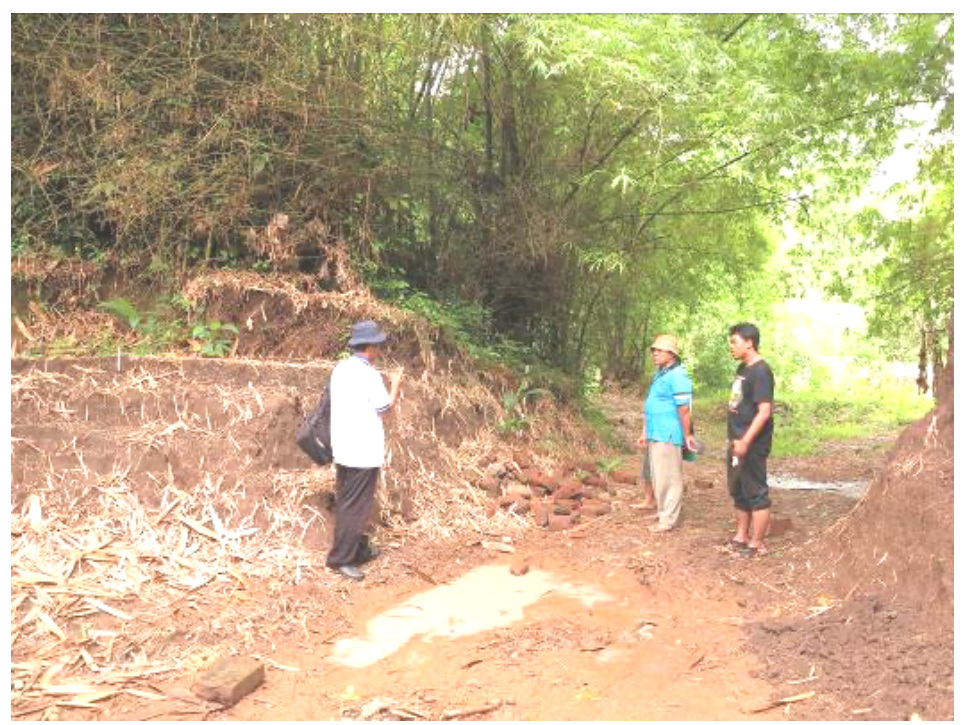

Gambar 4. Lokasi Runtuhan Bata Kuno di Kendalrejo (Danyangan Timo) (Sumber: Dokumen Balai Arkeologi Yogyakarta, 2012)

\section{Situs Kamulan}

Situs Kamulan berada di Desa Kamulan, Kecamatan Durenan, Kabupaten Trenggalek yang terletak pada koordinat $08^{0} 03$ ' 39,0” LS--1110 49' 31,3” BT. Dalam Siagian (2001), Situs Kamulan merupakan situs dengan struktur bangunan yang terbuat dari bata dan menurut informasi dari penduduk, di sekitar lokasi ini pernah ditemukan prasasti yag terbuat dari batu dan sekarang tersimpan di Museum Empu Tantular. Struktur bangunan ditemukan ketika dilakukan penggalian tanah oleh pemiliknya untuk pembuatan bata dan struktur bangunan tersebut diperkirakan merupakan bagian dari candi. Struktur bangunan berbahan bata ini bentuknya memanjang dari, arah utara ke selatan dan ditemukan pada kedalaman $75 \mathrm{~cm}$ dari permukaan tanah. Panjang struktur yang terlihat $210 \mathrm{~cm}$, terdiri atas 4 lapis bata dan ukuran bata berkisar antara $35 \mathrm{x} 20 \mathrm{x}$ $7 \mathrm{~cm}$ (Siagian, 2002).

Karakter Situs Kamulan mengacu pada hasil kegiatan survei arkeologi dan ekskavasi mengindikasikan sebagai situs pemukiman kuno. Hal ini didukung oleh lingkungan fisik yang baik, seperti ketersediaan air dan bentang lahan yang relatif datar. Keberadaan permukiman kuno ini didukung dengan data tertulis berupa Prasasti Kamulan yang berangka tahun 1164 saka atau 1194 Masehi yang sekarang tersimpan di Museum Wajakensis, Kabupaten Tulungagung. (Gambar 5) Prasasti Kamulan memberikan informasi bahwa prasasti tersebut merupakan sebuah tanah sima atau 
tanah yang bebas dari pungutan pajak kerajaan karena jasa Sāmya Haji Kataṇdan Sakapāt dan rakyatnya terhadap Sri Sarweswara Triwikramataranindita Srengga Lancana Dikwijayatunggadewa pada saat melarikan diri dari kaḍatuan yang berada di Katang-Katang sehingga tetap dapat menjalankan pemerintahan sebagai Șrī Mahārāja yang bertahta di Bhūmi Kadiri, karena itulah disetujuinya sebagai anugerah dari para dewa kepada Sāmya Haji Katạ̣̣an Sakapāt.... seperti yang tertulis dalam Prasasti Kamulan, yaitu șrī mahārāja tatkāla ni.... n kentar sangke kaḍatwan ring katangkatang deninkin malr yatik kaprabun șrī mahārāja siniwi ring bhümi kadiri matangyan inubhaya sanmata panghyang nikang sāmya haji kata(ṇ̦an sakapāt) (Priswanto, 2015a).
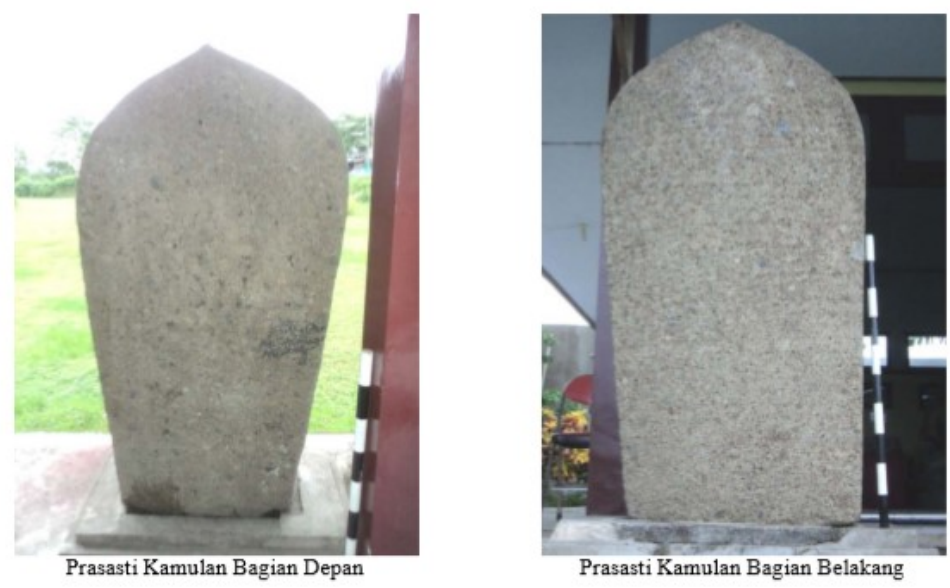

Gambar 5. Prasasti Kamulan yang Sekarang Berada di Museum WajakTulungagung (Sumber: Dokumen Balai Arkeologi Provinsi D.I. Yogyakarta, 2015)

Berdasarkan informasi narasumber, pada lokasi yang sama juga ditemukan sebuah prasasti yang dibuat oleh Raja Sri Sarweswara Triwikramataranindita Srengga Lancana Dikwijayatunggadewa atau lebih dikenal dengan sebutan Kertajaya, seorang raja Kediri yang berangka tahun 1116 Çaka atau 1194 Masehi. Prasasti Kamulan sekarang berada di Museum Wajakensis Tulungagung. Berdasarkan data artefaktual dan monumental yang ditemukan, Situs Kamulan diduga adalah sebuah situs permukiman dari masa peradaban awal yang merupakan situs permukiman masa peradaban Hindu Buddha, yaitu sekitar abad XII--XIII Masehi. Data artefaktual berupa fragmen tembikar dan fragmen keramik asing yang ditemukan di Situs Kamulan merupakan salah satu parameter bahwa lokasi ini merupakan sebuah situs permukiman. Hal ini diperkuat lagi dengan informasi sumber tertulis Prasasti Kamulan (1116 Saka/ 1194 Masehi) yang menyatakan bahwa Kamulan merupakan sebuah tanah sima atau tanah yang bebas dari pungutan pajak kerajaan (Priswanto, 2015a).

\section{Ancaman Banjir Sungai Ngasinan}

Lingkungan fisik situs-situs di sekitar Sungai Ngasinan sebagian besar berupa dataran aluvial yang dimanfaatkan untuk lahan pertanian dan permukiman. Fitur alam yang dominan adalah aliran Sungai Ngasinan serta beberapa aliran sungai yang berasal dari sebelah utara desa, seperti Kali Jurangbanteng dan Kali Sedongo. Sungai Ngasinan 
mengalir dari Trenggalek ke Tulungagung melalui wilayah Kec. Durenan bagian tengah. DAS Ngasinan merupakan salah satu bagian hulu Sungai Brantas yang terletak di wilayah Kabupaten Trenggalek dan Tulungagung, Provinsi Jawa Timur. Aliran Sungai Ngasinan dan Ngrowo berakhir di Sungai Brantas. DAS Ngasinan-Ngrowo ini merupakan salah satu hulu sungai Brantas, termasuk dalam DAS yang memiliki daerah tangkapan hujan paling luas jika dibandingkan dengan DAS yang lain. Pada wilayah Kabupaten Trenggalek bagian utara terbentang Pegunungan Rajegwesi, antara lain Pringulung, Condrogeni, Gunung Cilik Ngesong, Tumpak Cenil, Watu Blandong, Gunung Kekep, dan salah satunya Gunung Bale (Priswanto, 2012), yang secara imaginer membentuk sebuah morofologi cekungan di sekitar DAS Ngasinan.

Morfologi cekungan tersebut mengakibatkan endapan aluvial yang terakumulasi sangat tebal, didominasi material halus bertekstur lempung hingga pasir sebagai matriks utamanya, dengan sebaran fragmen kerikil berstruktur mengambang (kemas terbuka). Pada wilayah sebaran endapan aluvial ini mengalir sungai utama, yaitu Sungai Ngasinan sebagai sungai permanen (perennial), yang memperoleh pasokan air dari pola aliran yang cukup rapat, yang berhulu di wilayah-wilayah tinggi sekitarnya dengan pola aliran nyaris memusat (radial sentripetal) (Yuwono, 2017).

Alur sungai yang cenderung bermeander membuktikan bahwa muatan sedimen yang diangkutnya cukup besar, yang sebagian diendapkan di daerah dataran banjir, terutama di lengkung-lengkung bagian dalam kelokan yang membentuk point bar dengan lapisan yag tebal. Perbedaan ketebalan secara ekstrem ditunjukkan melalui perbedaan lapisan sedimen penimbun situs, antara Situs Kamulan yang relatif jauh dari aliran sungai dengan Candi Brongkah yang sangat dekat dengan Sungai Ngasinan. Keduanya merupakan contoh buried landscape (bentang lahan yang terkubur) di wilayah sebaran endapan aluvial di wilayah Trenggalek, yang pengungkapannya perlu memperhitungkan aspek-aspek geomorfologi setempat. Kondisi lanskap wilayah sebaran endapan aluvial ini (wilayah cekungan) tampaknya juga menjadi pertimbangan penting di dalam pemilihan lokasi permukiman pada masa klasik. Di samping sumber daya lingkungannya yang bagus, di antaranya lapisan tanah dan potensi air yang menjamin kesuburan lahan, fisiografinya juga menjamin faktor keamanan wilayah (Yuwono, 2017).

Bentuk perbukitan melingkar adalah benteng pertahanan yang sangat ideal bagi sebuah "kerajaan" meskipun keterhubungan dengan wilayah lain hanya dapat dilakukan melalui celah di sisi tenggara (sekitar Situs Kamulan) menuju daerah Tulungagung. Celah fisiografis ini pulalah yang menjamin sistem hidrologi setempat sebagai sebuah drainage basin (Daerah Aliran Sungai). Aliran Sungai Ngasinan sebagai semacam outlet menjamin kondisi hidrologis cekungan, yang sebenarnya merupakan zona akumulasi air permukaan, menjadi tidak terlalu lembap. Secara hipotetik, dapat diperkirakan pula bahwa peran daerah Kamulan pada masa lalu dalam pengendalian banjir sangat penting. Meskipun DAS Sungai Ngasinan tidak terlalu luas (terbatas pada wilayah di antara igir-igir/punggungan perbukitan yang mengelilinginya), material halus yang terangkut aliran permukaan, yang berasal dari rombakan batuan-batuan volkanik 
tua di perbukitan sekitarnya berpotensi menghasilkan endapan lempung yang tebal, yang dapat memperburuk drainase vertikal permukaan tanah. Potensi banjir yang dapat ditimbulkannya hanya dapat dikontrol melalui aliran Sungai Ngasinan dan wilayah di kanan-kirinya sebagai area pembuangan (discharge area) keluar dari wilayah cekungan (Yuwono, 2017).

\section{SIMPULAN}

Keberadaan situs-situs arkeologi di sekitar Sungai Ngasinan, seperti Candi Brongkah, Situs Semarum, dan Situs Kamulan terpendam akibat sedimentasi proses banjir yang sering terjadi dan terus-menerus oleh Sungai Ngasinan. Lokasi situs-situs arkeologi di sekitar Sungai Ngasinan yang berada pada morfologi cekungan yang mempunyai topografi yang landai, berada dekat dengan sumber air, dan mengandung tanah yang subur adalah sesuatu yang sangat ideal untuk pemilihan lokasi situs. Namun, pemilihan lokasi tersebut juga akan membawa dampak yang sangat signifikan dan risiko besar terhadap luapan air (banjir) karena posisinya yang landai dan berada di dekat daerah aliran sungai (DAS).

\section{DAFTAR PUSTAKA}

Daldjoeni (1984). Geografi Kesejarahan Indonesia I. Alumni.

Daniati, R.P., \& S. (2015). Tingkat Kerentanan Masyarakat terhadap Bencana Banjir di Perumnas Tlagasari, Kota Semarang. Jurnal Pengembangan, 3.

Erlina (2018). Analisis Banjir dan Sedimentasi Wilayah Sungai Brantas (Tinjauan terhadap Metode Pengendalian). Jurnal Teknik Sipil, XIII(1), 1-14. https://jurnal.ucy.ac.id/index.php/teknik_sipil/article/view/245.

Latief, Kusairi, et al. (2019). Banjir dan Upaya Penanganannya Pasca-Kemerdekaan tahun 1955--1971 di Tulungagung. Mozaik-Jurnal Ilmu-Ilmu Sosial \& Humaniora, 10.

Ma'ruf, Farid E.A. (2020). Kabupaten Trenggalek dalam Angka Tahun 2020.

Munandar, A.A. (2015). Keistimewaan Cand-Candi Zaman Majapahit. Wedatama Widya Sastra.

Piggot, S. (1958). Approaches to Archaeology. Adam \& Clark.

Priswanto, H. (2012). Penelitian Arkeologi di Situs Semarum, Desa Semarum Kecamatan Durenan, Trenggalek.

Priswanto, H. (2013). Bentuk \& Karakter Bangunan di Situs Semarum \& Situs Kamulan, Kecamatan Durenan, Kabupaten. Trenggalek (Tahap II) (Nomor Tahap II).

Priswanto, H. (2014). Bentuk \& Karakter Situs Semarum dan Kamulan di Kabupaten Trenggalek (Tahap III). 
Priswanto, H. (2015a). Bentuk dan Karakter Situs Kamulan, Desa Kamulan, Kecamatan Durenan, Kabupaten Trenggalek Jawa Timur. Laporan Penelitian Arkeologi.

Priswanto, H. (2015b). Hasil Penelitian Terbaru: Bentuk dan Karakter Situs Semarum. Berkala Arkeologi, 35, 133-144.

Priswanto, H. (2015c). The Latest Results: Form \&amp; Character of Semarum Site. Berkala Arkeologi, 35(2), 127. https://doi.org/10.24832/berkalaarkeologi.v35i2.61.

Rahman, K. (2016). Evaluasi dan Pengendalian Banjir di Kabupaten Trenggalek: Studi Kasus Banjir Agustus 2016. Conference: PIT HATHI XXXIIIAt: Semarang, November 2016, 509-518.

Siagian, R. (2002). Candi sebagai Warisan Seni \& Budaya Indonesia. Yayasan Cempaka Kencana.

Sumarkanto. (2002). Pencemaran Lingkungan Perairan Sungai Salah Satu Faktor Penyebab Banjir di Jakarta. Jurnal Teknologi Lingkungan, 3(1), 3.

Tanudirjo, D. A. (1988). Ragam Metoda Penelitian Arkeologi dalam Skripsi Karya Mahasiswa Arkeologi Universitas Gadjah Mada.

Utomo, D. W. (2012). Laporan Peninjauan Struktur Bata Kuna di Desa Semarum, Kecamatan Durenan, Kabupaten Trenggalek.

Yusuf, Y. (2005). Anantomi Banjir Kota Pantai: Perspektif Geografi. Pustaka Cakra.

Yuwono, J. S. E. (2017). Wilayah Trenggalek dalam Konteks Lanskap. Dalam Berita Penelitian Arkeologi "Bentuk \& Karakter Situs Semarum dan Kamulan di Kabupaten Trenggalek.” Balai Arkeologi Yogyakarta. 
PURBAWIDYA: — Vol 10, No. 2, November 2021: 155-166 